Review

\title{
Ash Management Review-Applications of Biomass Bottom Ash
}

\author{
Adrian K. James *, Ronald W. Thring, Steve Helle and Harpuneet S. Ghuman
}

University of Northern British Columbia, 3333 University Way, Prince George, BC V2N 4Z9, Canada; E-Mails: thring@unbc.ca (R.W.T.); helle@unbc.ca (S.H.); ghumanh@unbc.ca (H.S.G.)

* Author to whom correspondence should be addressed; E-Mail: ajames@unbc.ca; Tel.: +1-250-301-8141.

Received: 18 July 2012; in revised form: 13 September 2012 / Accepted: 20 September 2012 / Published: 9 October 2012

\begin{abstract}
In industrialized countries, it is expected that the future generation of bioenergy will be from the direct combustion of residues and wastes obtained from biomass. Bioenergy production using woody biomass is a fast developing application since this fuel source is considered to be carbon neutral. The harnessing of bioenergy from these sources produces residue in the form of ash. As the demand for bioenergy production increases, ash and residue volumes will increase. Major challenges will arise relating to the efficient management of these byproducts. The primary concerns for ash are its storage, disposal, use and the presence of unburned carbon. The continual increase in ash volume will result in decreased ash storage facilities (in cases of limited room for landfill expansion), as well as increased handling, transporting and spreading costs. The utilization of ash has been the focus of many studies, hence this review investigates the likely environmental and technological challenges that increased ash generation may cause. The presence of alkali metals, alkaline earth metals, chlorine, sulphur and silicon influences the reactivity and leaching to the inorganic phases which may have significant impacts on soils and the recycling of soil nutrient. Discussed are some of the existing technologies for the processing of ash. Unburned carbon present in ash allows for the exploration of using ash as a fuel. The paper proposes sieve fractionation as a suitable method for the separation of unburnt carbon present in bottom ash obtained from a fixed-bed combustion system, followed by the application of the gasification technology to particle sizes of energy importance. It is hoped that this process will significantly reduce the volume of ash disposed at landfills.
\end{abstract}


Keywords: ash management; unburned carbon; biomass; gasification; bottom ash; ash utilization; ash production

\section{Introduction}

In industrialized countries, it is expected that the future generation of electricity will be from the direct combustion of residues and wastes obtained from biomass [1]. Biomass boilers are one medium for efficiently combusting the biomass and obtaining its energy. According to Demirbas et al. [1], increased efficiencies can be attributed to large scale combustion processes, thus improving heat recovery. Many combustion technologies are available for biomass combustion such as fixed bed, fluidized bed and pulverized bed combustion [2]. According to Saidur et al. [2], fluidized bed combustion is the best technology to burn a fuel with low quality, high ash content and low calorific value. In addition, the authors noted that the other firing systems present limitations and are techno-economically unviable to meet the challenges of biomass fuel properties. Sandberg et al. [3] also noted that fluidized bed systems are the most suitable for converting biomass into energy, because of their ability to handle different fuels, flexibility, low operating temperature and low emissions.

Because of the high ash content that is present in biomass (see Table 1), boiler combustion processes are known to produce large amounts of ash. Also, as the demand for bioenergy production increases the ash and residue volumes will increase. Major challenges will arise relating to the efficient management of these products. The primary concerns are ash storage, ash disposal, ash usage and the presence of unburned carbon. The continual increase in ash volume will result in decreased ash storage facilities (in cases of limited room for landfill expansion), as well as increased handling, transporting and spreading costs.

Table 1. Properties of woody biomass samples [4,5].

\begin{tabular}{lcccccc}
\hline Proximate Analysis (wt \%) & Rice husk & Rice husk pellet & Larch dust & Willow & Miscanthus & Pine \\
\hline Moisture & 3.6 & 9.2 & 2.6 & 7.2 & 6.1 & 5.5 \\
Volatile matter & 60 & 65.1 & 76.7 & 78.1 & 67.9 & 81.2 \\
Ash & 16.3 & 9.3 & 0.8 & 1.0 & 12.9 & 1.2 \\
Fixed carbon & 20.1 & 16.4 & 19.9 & 13.7 & 13.1 & 12.1 \\
\hline
\end{tabular}

Due to the variety of biomass fuel sources with differing ash properties, finding one application that will be suitable for all of the ash is unlikely. Identifying the characteristics of the ash will provide valuable information as to the likely methods for processing. Gomez-Barea et al. [6] proposed three main utilization categories for fly ash derived from biomass: (1) Use in agriculture; (2) Use as fuel and (3) Use in construction.

The potential utilization of ash is influenced by contaminants such as heavy metals and the extent to which the ash is sintered [7]. Clean biomass contains minerals and important trace elements and therefore can be recycled to forest grounds, however, these trace metals must be clearly quantified and their impacts studied if they are to be applied to soils. Effective environmental monitoring and protection must be carried out to ensure that ash disposal does not become an environmental hazard. 
In addition, high levels of unburned carbon can be found in the ash produced from boilers. According to Demirbas [8], the fly ash from biomass-fired grate boilers contain high levels of unburnt carbon and is not suitable for recycling to the forest. Grate boilers often produce a fly ash with $50 \%$ or more of unburnt carbon. The presence of this carbon indicates inefficient fuel use and can reduce ash stabilization (chemical hardening) and significantly increases ash volume. If the carbon contents are to be reduced it would become necessary to reburn the ash.

The utilization of ash has also seen its application in the construction industry. According to Gomez-Barea et al. [6], fly ash can be used as a cement replacement in concrete, for soil stabilization, as a road base, structural filler in asphalt and asphalt base products, lightweight bricks and synthetic aggregate.

While much research has been conducted on fly ash utilization, a lot still remains to know about the effective management and utilization of bottom ash.

\section{Ash from Biomass Combustion}

The ash content of wood chips normally depends on the bark content of the mixture since the minerals are usually more concentrated in that region [9]. Ash is the inorganic uncombustible part of fuel left after complete combustion, and contains the bulk of the mineral fraction of the original biomass [7]. Ash is an integral part of the plant structure and consists of a wide range of elements [10]. In wood, ash represents less than 2 percent, while in agricultural crop materials it can be $5 \%-10 \%$ and up to $30 \%-40 \%$ in rice husks and milfoil.

Biomass-based products produce solid residue ash, a result of thermochemical degradation. These thermochemical processes include combustion, pyrolysis, and incineration of woody biomass. Bottom ash and fly ash are usually the two types of ash produced and may vary in properties due to the different types of biomass available, operating conditions and the type of system used. High ash contents significantly reduce the energy output derived from a specific biomass source.

\section{Estimate of Potential Increase in Ash Production}

An estimate of the potential ash production may be derived by carefully studying the amounts of woody biomass that are used or may be used for processes that produce ash. The analysis of Table 1 presents an example of the percentage composition of ash varying based on different types of woody biomass. Subsequently this composition along with the quantity of biomass produced can be used to estimate the total amount of ash produced.

Wood residue forms a significant input for energy related uses such as in gasification, pyrolysis, combustion and other systems based on harnessing the energy potential of woody biomass. Wood residues are defined by the FAO [11] as wood by-products which have not been reduced to small pieces. They consist principally of industrial residues, e.g., sawmill rejects, slabs, edgings and trimmings, veneer log cores, veneer rejects, sawdust, bark (excluding briquettes), residues from carpentry and joinery production, etc. Residues produced at industrial processing sites, like bark and sawdust in sawmills, are the largest commercially used biomass source [12].

According to the Food and Agriculture Organization (FAO) [11], approximately $98.2 \times 10^{7} \mathrm{~m}^{3}$ of wood residue was generated globally, as a yearly average from 1992 to 2010 . For the sample period 
the top five wood residue generating countries produced $15.3 \times 10^{7} \mathrm{~m}^{3}$ from China, $14 \times 10^{7} \mathrm{~m}^{3}$ from Brazil, $13 \times 10^{7} \mathrm{~m}^{3}$ from USA, $7.9 \times 10^{7} \mathrm{~m}^{3}$ from the Russian Federation and $7.7 \times 10^{7} \mathrm{~m}^{3}$ from France. These residues have the potential for supplementing current wood fuel consumption. Comparing these statistics to coniferous wood-fuel used, USA had $9.5 \times 10^{7} \mathrm{~m}^{3}$ of wood-fuel, $91 \times 10^{7} \mathrm{~m}^{3}$ for China, $13 \times 10^{7} \mathrm{~m}^{3}$ for Brazil, $19 \times 10^{7} \mathrm{~m}^{3}$ for the Russian Federation and $2.7 \times 10^{7} \mathrm{~m}^{3}$ for France in 2010. This data can help us draw some conclusions about ash production from the current wood-fuel use, and the potential increase in ash production from the combustion of wood residues. Ash produced from wood residue or wood chips has distinct chemical and physical properties that vary in part due to factors such as origin of biomass, type of energy harnessing process, chemical reactions occurring during high heat conditions in the furnace and storage and treatment of fuel [13]. Literature reported values vary between $1 \%$ (wt \%) ash content for clean wood without bark to $5 \%-15 \%$ ash content for contaminated bark [14]. An estimate of the ash generated from potentially using wood residue may be obtained. Table 2 reports bulk densities for different kinds of residual woody biomass. We may use these values and arrive at an approximate value of bulk density for wood residue, equivalent to $0.16 \mathrm{ton} / \mathrm{m}^{3}$ and $0.21 \mathrm{ton} / \mathrm{m}^{3}$ for wood chips and wood fuel.

Table 2. Bulk densities of different types of wood [15].

\begin{tabular}{cc}
\hline Wood & Bulk density $\left(\right.$ ton $\left./ \mathbf{m}^{\mathbf{3}}\right)$ Dry ash free tonnes \\
\hline Hardwood chips & 0.23 \\
Softwood chips & $0.18-0.19$ \\
Sawdust & 0.12 \\
Planer Shavings & 0.10 \\
\hline
\end{tabular}

Assuming that the entire wood residue produced in the world were to be incinerated, gasified or combusted to harness energy we can use the bulk density of residue and weight percentage of ash to establish an approximation of the ash produced. Table 3 shows the ranges of ash produced from fuel wood and the potential addition by increasing the use of residual woody biomass in combustion, incineration or pyrolysis processes.

Table 3. Estimate of potential ranges of net ash production based on complete wood residue utilization in global leaders of wood residue generation, and complete wood fuel utilization in global leaders of wood fuel production. The lower and upper limits use 5\% and $10 \%$ (wt \%) ash respectively.

\begin{tabular}{lcc}
\hline Country & $\begin{array}{c}\text { Ash from wood residue combustion } \\
\left(\mathbf{1 0}^{\mathbf{5}} \text { tons) }\right.\end{array}$ & $\begin{array}{c}\text { Ash from wood fuel combustion } \\
\left(\mathbf{1 0}^{\mathbf{5}} \text { tons) }\right.\end{array}$ \\
\hline China & $1.2-2.4$ & $9.5-19.1$ \\
Brazil & $1.1-2.2$ & $1.4-2.7$ \\
USA & $1.04-2.1$ & $0.99-2.0$ \\
Russia & $0.63-1.3$ & $1.99-4.0$ \\
France & $0.61-1.2$ & $0.28-0.57$ \\
\hline
\end{tabular}


The ash is fixed at 5\%-10\% (wt \%) for wood used in a commercial and large scale energy systems. The lower limit of $5 \%$ and the upper limit of $10 \%$ will give a good range for the quantities of ash produced. This range is relatively higher for clean wood without bark $(<1 \%$ ash $)$, but seems to fit the values for the ash content of dominant types wood present in the wood available for use. These include: bark (3\%-4\% ash), contaminated bark (5\%-15\%), contaminated reject wood $(0.5 \%-19 \%)$ and clean reject wood $(0.5 \%-3 \%)$ [14]. We must also consider studies that suggest the actual amount of ash generated is higher due to inefficiencies in the boilers and furnaces. This range will be used to calculate the upper and lower approximates of ash produced from fuel-wood and wood residue. These values for the upper and lower limits of ash produced are reported in the Table 3.

According to Obenberger et al. [16], while the 2005 production of ash in European Union amounted to $5.6 \times 10^{7}$ tons, the future trend in biomass for energy is expected to double by 2020 , and might lead to production of $15.5 \times 10^{7}$ tons of ash in the EU-27. Our estimates of current ash production fall into proportion, as Europe produced $140 \times 10^{7} \mathrm{~m}^{3}$ of fuel wood for 2005 . This translates to about a range of $1.6 \times 10^{7}$ to $3 \times 10^{7}$ tonnes of ash produced in 2005 from domestically produced fuel wood. Fuel wood imports and industrial utilization of wood residues are not considered in this estimate. They also contribute positively to the net ash production of a region. A detailed calculation of the total ash produced is difficult to determine. This is due to the lack of understanding and information about all biomass sources and their net contribution to ash production processes.

Literature reported values for current biomass use as a fuel compared to its potential use, vary from $16 \%$ in North America, $12 \%$ in Latin America, 22\% in Europe and 108\% in Asia $[12,17,18]$. This averages to $38 \%$ for the world $[12,17,18]$. This implies that countries such as USA, Canada, and other European nations have immense potential for developing bio-energy based technologies. These figures point out clearly to a future increase in exploitation of this potential, and a subsequent increase in ash generation. Limited understanding of ash behaviour and its environmental impacts acts as a hindrance for the complete utilization of combusted wood residue. The probable alternative fate for most wood-processing residues currently used for power production is landfill disposal [19].

\section{Elements in Ash of Environmental Significance}

The major inherent ash forming elements in biomass include $\mathrm{Ca}, \mathrm{Si}, \mathrm{Al}, \mathrm{Ti}, \mathrm{Fe}, \mathrm{Mg}, \mathrm{Na}, \mathrm{K}, \mathrm{S}$ and $\mathrm{P}[7,9]$. The composition of ash affects its behavior under high temperatures of combustion and gasification reactors [10]. These problems may include clogged ash-removal caused by slagging ash, sintering, deposition, erosion, corrosion and pollutant emissions that are mainly created by the presence of alkali metals, alkaline earth metals, silicon, chlorine and sulphur in the ashes [10,20,21].

\subsection{Presence of Metals in Ash}

The presence of volatile heavy metals contained in ash residue may also have negative environmental impacts if irrationally managed and disposed, due to the possible leaching into underground and surface waters [20]. According to Khan et al. [7], the potential utilization of ash is influenced by contaminants such as heavy metals which are often present depending on the biomass source. According Demirbas [8], the composition of ash is dependent on the plant species, growth conditions and ash fraction. For example, Vamvuka [20] work suggested that the high concentration of 
the $\mathrm{Ni}$ and $\mathrm{Cr}$ present in the olive kernel ash under study was most likely due to the soil parent material. According to the author the soil type is laden with $\mathrm{Ni} / \mathrm{Cr}$ which is transferred to the plant through rootlets. Wood ash generally has a higher concentration of $\mathrm{As}, \mathrm{Cd}, \mathrm{Pb}$ and $\mathrm{Hg}$ than agricultural residue, such as the ash from wheat, straw and fruit shells.

While the Khan et al. [7] review pointed out that the heavy metals are typically concentrated in fly ash, these metals, though lower in concentration, are also present in bottom ash. With the large quantities of bottom ash being generated annually, their metal concentrations and the cumulative metal concentrations from deposition and landfilling must be investigated. Vamvuka [20] investigated the thermal behaviour of olive kernel ash that was produced in a fixed and fluidized bed combustor. The environmental impacts of the ash upon disposal to local soils were also analyzed. A $150 \mathrm{~cm}$ long with $7 \mathrm{~cm}$ inner diameter cylindrical stainless steel lab scale reactor tube was used. For the fluidized bed, olive kernel with $1 \%$ moisture was fed at a rate of $480 \mathrm{~kg} / \mathrm{h}$ to a bed temperature of $900{ }^{\circ} \mathrm{C}$. A batch of $0.5 \mathrm{~kg}$ fuel was loaded for the fixed bed and air was supplied at $6 \mathrm{~m}^{3} / \mathrm{h}$ with an excess of $20 \%$ to ensure complete combustion. Bottom and fly ash samples were collected and analyzed for each reactor. According to Vamvuka [20], the elements $\mathrm{Cr}, \mathrm{Cu}$, Ni and $\mathrm{Mn}$ were enriched in olive kernel ash derived from fixed bed experiments, while the toxic elements $\mathrm{Se}$ and $\mathrm{Pb}$ were below $9 \mathrm{ppm}$. Cr had the highest concentrations of $2000 \mathrm{ppm}$ which the researcher attributed to the soil parent type of the fuel. The results also showed that trace elements were very low in cyclone ash and may have escaped in the flue gas due to the short time for re-condensation during fluidised bed combustions. The leachates analysis produced negligible quantities ( $\mathrm{ppb}$ ) of all constituents except $\mathrm{Cr}$, Se and $\mathrm{Pb}$ levels, $<3 \mathrm{ppb}$ were found to be the lowest and $\mathrm{Mn}$ the highest at $5872 \mathrm{ppb}$.

\subsection{Applications of Ash for Soil Amendment and Agriculture}

However, some mineral nutrients of the ashes may have a vitalizing effect on its application to agricultural or forests soils. Olanders et al. [9] in their work reported that the ash from biomass fuel contains only trace amounts of heavy metals, which makes them fairly easy to dispose of and they can be good fertilizers. A two part research was carried out by Gomez-Barea et al. [6] in which they looked at the optimization of the operating conditions to achieve better ash quality and then assessing the ash quality in order to explore its potential utilisation. Two types of biomass, orujillo and meat and bone meal (MBM) were gasified in a bubbling fluidized bed gasifier with bed materials ofite and limestone. The operating temperatures ranged from 700 to $850{ }^{\circ} \mathrm{C}$ with a fuel feed rate of $6-35 \mathrm{~kg} / \mathrm{h}$. The potential utilisation of ash as a soil conditioner, soil rehabilitation and plant growing medium, soil nutrient and fertiliser and as a neutralizing agent and liming agent was investigated.

High concentrations of $\mathrm{P}$ and $\mathrm{Ca}$ were found in $\mathrm{MBM}$ ashes while high $\mathrm{K}$ levels were found in orujillo ashes but low solubility levels were obtained for these elements for both fuel types (Gomez). $\mathrm{P}$ in MBM ashes measured a solubility level of less than 1\% in DIN leaching test. The research concluded that due to this low solubility of $\mathrm{P}$ and $\mathrm{Ca}$, the use of these ashes in common soils were doubtful for use as a fertilizer. In relation to the heavy metals, both orujillo and MBM ash had a high Cr concentration but was thought to be as a result of the decomposition of the steel in the reactor from abrasion. Of concern in this research according to Gomez-Barea et al. [6], was the $\mathrm{Cl}$ content of the orujillo ash, which they highlighted as probably the main handicap of this ash. A $\mathrm{Cl}$ content of $0.5-1.5 \mathrm{wt} \%$ was 
obtained for the fuel. Both MBM and orujillo had a high PAH, around $100 \mathrm{mg} / \mathrm{kg}$. While sustainable methods are constantly being sought for the utilisation of fly ashes Gomez-Barea et al. [6] concluded that fly ash from these two waste were not suitable for some applications because of the high carbon content, chlorine content, alkali content and in some cases heavy metal content. Physical or thermal pre-treatment of the ashes were proposed so as to make the ash more usable. A few suggestions included: washing so as to remove alkali or chlorine content, applying low temperature combustion for carbon removal and using high temperature treatments for more persistent contaminants. The fly ash from waste material gasification did not meet the requirements for fertilisers. These requirements were in accordance with the utilization standards for, Metal limit values for ash utilization in cultivation in Finland and recommended minimum and maximum values for components in ash produced in Sweden.

In similar research conducted by Nurmesniemi et al. [22], the physical and chemical properties of bottom ash and fly ash obtained from a $115 \mathrm{MW}$ bubbling fluidized bed combustion plant was investigated. One problem cited as influencing the research was the rapid increase in large amounts of fly and bottom ash generation due to the increase use of wood-based biomass for energy production. These energy sources are considered to be carbon neutral. Other problems included the increase costs of landfill disposal in the form of waste tax or deposit fee as well as the difficulties in acquiring new landfill sites and stricter EU landfill directives. Hence, the need to find recycling options for ash. Ash from the bubbling fluidized bed boiler operated at $800{ }^{\circ} \mathrm{C}$ was withdrawn and stored at $4{ }^{\circ} \mathrm{C}$ in a refrigerator. A strong alkaline $\mathrm{pH}$ value of 11.9 was recorded for the bottom ash. This was attributed to some of the dissolved metals occurring as basic metal salts, oxides and carbonates.

In relation to the liming effect of the ash, Nurmesniemi et al. [22] investigated the acid neutralizing value (NV) by looking at the cations of $\mathrm{Ca}, \mathrm{Mg}$ and $\mathrm{K}$. A NV 8.7\% (Ca equivalents, d.w.) was obtained for bottom ash which they suggested that a ca. of 4.4 tonnes of this residue would correspondingly be required to replace 1 tonne of commercially ground limestone. The research concluded that fly ash would act as a better soil liming agent to neutralize soil acidity than bottom ash. While the research agrees that fly ash is a better forest fertilizer, plant nutrient agent and soil improvement agent than bottom ash, the large quantities of bottom ash generated makes it of environmental importance. For the bottom ash, elements such as $\mathrm{Mg}, \mathrm{Ca}$ and $\mathrm{K}$ concentrations (d.w.) were $0.6 \%, 6.0 \%$ and $2.6 \%$ respectively while fly ash concentrations were $2.6 \%, 20.5 \%$ and $3.9 \%$ respectively. The researchers noted that the $\mathrm{Cl}$ levels were also below the Finnish maximum limit value $(2.0 \%$; d.w.) recording $<0.1 \%$ for bottom ash and $0.5 \%$ for fly ash.

A total $\mathrm{P}$ of $0.3 \%$ (d.w.) with a negligible water soluble $\mathrm{P}$ content was recorded for bottom ash. The research noted that water soluble $\mathrm{P}$ is the amount of $\mathrm{P}$ that is readily available to plants. The poor water solubility of $\mathrm{P}$ was highlighted as a draw back in the application of wood ash to soils since only a small portion $\mathrm{P}$ is extractable and available for plants when used in forest fertilizers. On the other hand, the paper referenced Moilanen et al. [23], who suggested that water-insoluble forms of $\mathrm{P}$ in forest fertilizers minimise the risk of $\mathrm{P}$ leaching into water bodies.

The research highlighted two heavy metals, $\mathrm{Cr}$ and $\mathrm{Pb}$ having concentrations that were 1.8 and 110 times higher in fly ash than bottom ash, respectively. The bottom ash concentrations for $\mathrm{Cr}$ and $\mathrm{Pb}$ were $39 \mathrm{mg} / \mathrm{kg}$ and $<3.0 \mathrm{mg} / \mathrm{kg}$, respectively. Nurmesniemi et al. [22] concluded that the concentrations of all elements in the fly and bottom ash were lower than the Finnish limit values and therefore does not restrict the use of wood ash as a forest fertilizer. 
Dahl et al. [24] conducted a series of similar studies on the heavy metal concentrations in bottom ash and fly ash fractions from a large-sized (246 MW) fluidized bed boiler with respect to their Finnish forest fertilizer limit in values. The study assessed whether the physical and chemical properties, nutrients and heavy metals concentrations in the various ash fractions supported their use as a forest fertilizer. $50 \%$ of the fuel was from forest residue while the other 50\% was from commercial peat fuel. The results were in agreement with many of the other studies, obtaining high nutrient concentrations for the ashes. This would suggest the possibilities of utilizing bottom ash and fly ashes as a forest fertilizer. Dahl et al. [24] indicated that these ashes should be put to better use than to be deposited at a landfill. In addition, the authors suggested that ash utilization should be seen as an example of sustainable utilization of industrial residue since minerals would be returned to the forest environment and would reduce the need for fertilizers. In all cases, the fly ash concentrations were higher for all the heavy metals and alkali metals under study than bottom ash. However, a point of interest in the results was that the $\mathrm{Hg}$ content in the bottom ash was too low for detection. With $\mathrm{Hg}$ being one of the elements of extreme environmental scrutiny a low concentration is undoubtedly preferred in biomass ash.

Another interesting finding of this research related to the element As. A slightly elevated As concentration of $40 \mathrm{mg} / \mathrm{kg}$ (d.w.) was seen in one of the fly ashes under study [24]. According to the paper, the Finnish limit for this metal was $30 \mathrm{mg} / \mathrm{kg}$ (d.w.), which makes the fly ash containing $40 \mathrm{mg} / \mathrm{kg}$ of As unsuitable for use as a forest fertilizer. On the other hand, if both fly ashes were combined the residue could be suitable for use as a fertilizer since all other fly ash at different particle sizes were all below $10 \mathrm{mg} / \mathrm{kg}$ (d.w.).

Most of these researchers mentioned above seem to consider ash as an effective fertilizer and soil amendment property. While fly ash in some cases seems to contain high amounts of heavy metals, alkali metals and PAH which may exceed the allowable environmental limits, bottom ash appears to fall within the allowable limit. However, larger quantities of this bottom ash residue would be required to provide the adequate soil nutrients.

Considering the facts that ash fractions have varied concentration of metals, the application of a mixture of bottom and fly ash to soils could also be explored. The utilization of bottom ash has the advantage of lower heavy metal concentrations but the disadvantage of higher nutrient losses. Mixtures of fly ash and bottom ash may be useful to achieve optimum nutrient delivery within limits for heavy metal concentrations [16]. Also, if there is significant ash recycling to soil, bottom ash and some fly ash could be combined while the additional fly ash would be directed to landfill or other uses in order to prevent build-up of heavy metals.

It is also important to consider the origin of the biomass source and the characteristics of the ash that will be produced. For example, Rejinders et al. [25] referenced the Minnesota Office of Environmental Services [26] who reported that the wet disposal of coal ash has been related to abnormalities in animals. The elemental concentrations may vary with ashes from biomass or coal or other combustion materials. In light of this, the ash from each fuel source must be carefully analyzed before land applications are considered. Perhaps, constant testing and monitoring of landfills could also provide valuable information as to the cumulative long-term impacts that ash storage could have. This could provide valuable information as to likely changes over time if applied to soils.

Questions relating to the authenticity of the leachate test have also arisen. Reijnders et al. argue in a review [25] that it is possible that an accurate analysis of the leaching test conducted in the laboratory 
may not accurately reflect the leaching behaviour in the field. The review noted that reactions such as weathering, the dissolution of amorphous phases, the formation of minerals, the effect of flow conditions, ionic strength of pore solutions and kinetically determined processes can never be truly determined from the laboratory phase.

\section{Technologies in Place for Processing Unburned Carbon in Ash as a Fuel}

As previously mentioned, high contents of unburned carbon in bottom ash or fly ash indicates inefficient fuel use [8]. This unburned carbon concentration often varies for combustion systems and has led a number of researchers to investigate the varying reasons for this change as well as to determine the amounts of carbon that may be present in combustion ashes. According to Bahadori et al. [27], when coal is combusted a potential significant loss is that of unburned carbon. According to Gomez-Barea et al. [6], the carbon present in fly ash is generally present in large amounts, typically $10 \%-60 \%$ of the ash mass while Duan et al. [28] suggested a range of $10 \%-30 \%$. Their work referenced Turner et al. [29] supporting the idea that all coal-fired steam generators and coal-fired vessels inherently suffer an efficiency debit attributable to unburned carbon. Duan et al. [28] highlighted two possible reasons for the high carbon content in fly ash of Circulated Fluidized Bed (CFB) boilers as the short residence time, resulting in incomplete burnout of char and the high ash content which covers the char and prevents the free movement of gases to the core of the char. There is a need to find efficient technologies that could be used to reduce unburned carbon content in both fly ash and bottom ash. Additionally, optimizing the use of existing technologies could also improve combustion efficiency.

Demirbas [8] proposed that the fly ash could be reburned to remove additional carbon and that CFB boilers are suitable for doing so since they are fuel-flexible and produce well burnout ashes. The review noted that unburnt carbon has replaced $1 \%-2 \%$ of the fuel input to a CFB boiler, reducing fuel costs and NOx emissions by about 20\%-30\%depending on the amount of ash. However, Gomez-Barea et al. [6] looked at the idea of recycling fly ash in gasifiers but concluded that this processing method would be technically impossible. While the researchers considered fly ash from biomass to be a rational option as a fuel source in boilers and power plants, the heavy metals, as well as $\mathrm{Cl}$ and $\mathrm{K}$ would severely limit the mixing of these ashes with specific biomass before feeding the boiler. The paper cited corrosion-derived problems caused by $\mathrm{K}_{2} \mathrm{O}$ and $\mathrm{HCl}$ as major reasons for rejecting the technique. However, useful suggestions were offered as to how to effectively reduce the carbon content in the cyclone fly ash by their investigation of the impact of bed temperature on carbon content. When orujillo was gasified at different temperatures, the carbon content in the fly ash decreased when temperature was increased [6]. At $700{ }^{\circ} \mathrm{C}$ the carbon content was $20.18 \%$ while at $820{ }^{\circ} \mathrm{C}$ the carbon content reduced to $9.09 \%$.

Duan et al. [28] investigated a fly ash recirculation technique called fly ash recirculation by bottom-feeding (FARBF). The fly ash was recirculated from the bottom of the dense bed to the air plate. A FARBF system was installed on a $75 \mathrm{t} / \mathrm{h}$ boiler burning mixture of $60 \%$ coal sludge and $40 \%$ Chinese medium coal and was operated between the $980-1050{ }^{\circ} \mathrm{C}$ for the dense bed and $850{ }^{\circ} \mathrm{C}$ for the secondary zone. The experiments were accomplished by varying the recirculation rate, making it $0 \%$, $25 \%, 50 \%, 75 \%$ and $100 \%$ of the total fuel ash fed into the furnace. Each test was carried out for $4 \mathrm{~h}$ 
until a stable condition was achieved. The boiler dense bed temperature decreased from $960{ }^{\circ} \mathrm{C}$ to $880{ }^{\circ} \mathrm{C}$ with a $70 \%$ recirculation rate. This change was considered to be as a result of the fly ash absorbing heat when recirculated from the bottom of the boiler. The unburnt carbon in fly ash saw a decrease from $14.1 \%$ to $7.5 \%$ as the recirculation rate increased from 0 to $8 \mathrm{t} / \mathrm{h}$ and from $14.1 \%$ to $8.8 \%$ with a $70 \%$ recirculation. Duan et al. [28] explained that these results were obtained due to the intensive material turbulence inside the dense bed, crashing into the shell of the ash and exposing the unburnt carbon to the high temperature environment. Longer residence times were also said to influence burning out of the coal particles. The researchers concluded that FARBF can help to reduce the unburnt carbon in fly ash thus improving combustion efficiency.

Batra et al. [30] looked at characterizing the unburned carbon in bagasse fly ash obtained from two different sugar mill boilers in India and found more than $25 \%$ present. They noted that the unburned carbon posed disposal problems, presented obstacles when used in cement compositions and would therefore be better if used for other applications. The research showed that, industrially, carbon separation can be carried out using industrial scale sieve shakers for removal of the coarse carbon rich fraction. Three fractions were investigated, "as-received" fraction, sieve fraction greater than $425 \mu \mathrm{m}$ and fractions between 150 and $425 \mu \mathrm{m}$. Maximum carbon removal was obtained when a sieve fraction greater than $425 \mu \mathrm{m}$ was used or when a separation by fraction floatation in water was used. This conclusion was carried out by thermal gravimetric analysis for the different fractions. The study concluded that over $25 \mathrm{wt} \%$ of unburned carbon is present in bagasse fly ash. They proposed that the high carbon content present in boiler fly ash could be used as household fuel or gasifier feed after briquetting or pelletizing.

Carbon content in wood-ash has a direct impact on process efficiency and ash recycling in that, as more carbon is converted the higher the efficiency and the lower the volume of ash generated. While there is obvious potential for bottom ash to be recycled as fuel not much research has gone into the area. The researches mention mostly the idea of recycling ashes into a CFB. However, the need for more critical analysis of the unburned carbon present in bottom ash and effective ways of capturing this energy as a fuel need to be investigated. Most papers seem to suggest that there is only energy potential in ash if pelletized or briquetted. As mentioned previously, the carbon content in ash varies depending on the processing conditions, types of combustion equipment and fuel source. Subsequently, process efficiencies will vary, affecting the degree of unburnt carbon that may be present in ash. Therefore, a backup system or technology should be in place to deal with variations of carbon that may be present in the waste or combustion residue. This will not only improve efficiency but will reduce the volumes of ash produced as well as the additional costs incurred for disposal.

\section{Reviews and Suggestions of Proposed Ash Processing Methods}

Most of the work on ash and the presence of unburned carbon have been on fly ash especially from coal. However, more research needs to be undertaken relating to bottom ash as the volumes significantly increase industrially. Effective recycling and processing measures must be identified to ensure maximum energy use so as to eliminate some of the ash related storage and disposal problems.

The presence of unburned carbon in bottom ash suggests its potential for uses other than as a waste product. In this proposal, we present the separation of unburned carbon in wood biomass bottom ash 
from a fixed-bed combustion system by sieve fractionation, followed by the application of the gasification technology to particle sizes of energy importance.

Demirbas et al. [1] in a review pointed out that biomass gasification is the latest generation of biomass energy conversion processes and is being used to improve the efficiency and to reduce investments costs of bioelectricity generation. According to Quaak [10], gasification produces gaseous fuel that is easily handled, produces very little excess air when combusted and contains low levels of contaminants. For this reason, a gasifier may be used to harness any additional energy that the conventional boiler could not obtain by using the boilers waste as a fuel for the gasifier.

Biomass gasification is one of the technologies of energetic use of biomass as heat and electricity may be produced from using such process [31,32]. It is a thermochemical process of gaseous fuel production by partial oxidation of a solid fuel [32]. In this process, the chemical energy of the solid fuel is converted into the chemical and thermal energy of the product gas. The result of gasification is the producer gas, containing carbon monoxide, hydrogen, methane and some other inert gases [31].

An updraft fixed gasifier may be used to combust the unburned carbon. Fixed bed gasifiers are relatively simple, high charcoal burnout and an internal heat exchange that leads to low gas-exit temperatures and high energy efficiencies [10,32]. The system also allows for variation in fuel particle sizes as it is able to process relatively small fuel particles [10]. The presence of tars in the product gas is usually a concern in this system. However, it is anticipated that the boiler ash will have very little negative impacts on the gasifier as it relates to the presence of tars. This is because most of the tar would have been consumed from the boiler combustion stage. Of particular concern is the potential slagging that may result due to the high ash content of the feedstock. According to Quaak et al. [10] the updraft gasifier is able to accommodate fuels with a maximum moisture content of $60 \%$, particle size $5-100 \mathrm{~mm}$, maximum ash content of $25 \%$ and should be able to produce $5-6 \mathrm{~kJ} / \mathrm{Nm}^{3}$.

The energy recovery may be measured based on the composition of the gases produced. Hence, the ash-carbon content will be reduced using gasification with energy recovery in the form of heat and syngas production. The application of gasification technology in the reduction of ash-carbon content and the ability to recover any useful energy in the combustion residue presents promising prospects.

In order to separate and characterize ash and unburned carbon based on its particle size, the "as-received" ash must be separated in its fractions by sieving. Sieve sizes ranging from 0 to $2000 \mu \mathrm{m}$ may be used but the upper limit is based on the size of combustion residue obtained. Each separated fraction must be characterized in terms of its physical and chemical properties in order to identify fractions in bottom ash with high organic/carbon content and those with high mineral content as well their impact on the overall volume of ash stored or disposed of. Based on their characteristics, suitable applications for each fraction can be determined.

Limited information and results were found relating to the sieving of ash for unburned carbon recovery. Alternate suggestions for effective utilization of inorganic content in ash included the pre-treatment of ash whether by washing or sieving [6]. It is hoped that some metals could be washed and $\mathrm{Cl}$ in particular could be removed from these ash fractions using these techniques.

According to Dahl et al. [24] sieving methods have been applied to process ash containing heavy metals, separating them into various fractions. This separation produces ash fractions with low heavy metal concentrations, making them applicable in road construction and cement blends. Sieves were used to separate ash into particle sizes $2.0-0.5,0.5-0.125$ and $<0.125 \mathrm{~mm}$. The elemental 
concentrations of the heavy metals were noted based on the particle fraction. The bottom ash remained within the limits of elemental concentrations for all the particle sizes, however, one fly ash of particle size lower than $0.125 \mathrm{~mm}$ exceeded the limit value of $\mathrm{As}$, while $\mathrm{Pb}$ exceeded its environmental limit within particle size $0.5-2.0 \mathrm{~mm}$. However, it should be note that any pre-treatment will incur additional processing costs.

It is anticipated that fractions containing high levels of unburnt carbon could be a useful fuel source in the gasification process. As previously mentioned, some researchers have proposed pelletizing or briquetting bottom ash for fuel use. Research results for pelletization of bottom ash for use as a fuel could not be found, even after an extensive literature search. However, limited papers and studies exist as it relates the pelletization of bottom ash from biomass for other uses. In must be noted that this process comes with inherent challenges. According to Lövgren et al. [13], a high content of unburnt organic matter interferes with the agglomeration of ash particles. To deal with this situation, pelletizing (roll pelletizing) has proven to be an efficient method. This method helps to prepare ash for recycling of basic cations, and acid neutralizing lime components back to the forest [33,34].

Several studies have described hardening and carbonation (treatment with carbon dioxide) of ash as an effective method to handle ash. Accelerated carbonation positively affects the hardening of an ash product, which may then be easily transported and used as a fertilizer. Also, well hardened products show slow leaching patterns, which are considered good for applications in fertilizing land [35-37]. However, it is difficult to harden ash with high carbon content.

In a TNO Report [14], it pointed out that if ash is to be re-used it is important to know its particle size and particle density. These will better aid in understanding the potential of ash for environmental applications and its contribution to reducing ash volumes. Obtaining the bulk densities for various particle sizes could give valuable information on dumping and storage cost. According to the TNO-report, the dumping costs in The Netherlands can be relatively high. A point of interest is that ashes produced from different wood sources may vary in bulk densities. The report suggested that the difference in bulk densities were relative to the fuel source and the combustion process and technology employed (See Table 4).

Table 4. Showing particle size and bulk density in the combustion of sawdust and shredded wood [14].

\begin{tabular}{clcc}
\hline \multicolumn{2}{c}{ Type of fuel ash fraction } & Particle size $(\boldsymbol{\mu m})$ & Bulk density $\left(\mathbf{k g} / \mathbf{m}^{\mathbf{3}}\right)$ \\
\hline \multirow{2}{*}{ Sawdust } & Grate fire ash & $10-30.000$ & 662 \\
& Cyclone fly ash & $2-100$ & 283 \\
\multirow{2}{*}{ Shredded Wood } & Grate fire ash & $15-15.000$ & 960 \\
& Cyclone fly ash & $2-160$ & 430 \\
\hline
\end{tabular}

\section{Technological Implications When Processing Ash}

While there are obvious benefits to some soil properties other ash related problems remain as some of the main obstacles to the economical and viable applications of biomass gasification [21]. According to Vamvuka [20], the successful design of a combustion system using agro-residue as feedstock will partly depend on the ability to control the technical and environmental problems associated with the inorganic constituents. 
During combustion some of the inorganic species formed are as a result of the interactions with the organic portion of the biomass. According to Olanders et al. [9], the organic structures are decomposed and the ash formers are released. The alkaline earth metals leave the combustion zone as solid particles while the alkaline metals are transported in vapor form as chlorides, hydroxides and oxides. These species can react with $\mathrm{SO}_{2}$ to form sulphate particles which results in the formation of hard deposits on surfaces leading to corrosion problems [9,38]. Olanders' et al. [9] research showed that the first steps in ash-forming process involves calcium, potassium, silicon, sulphur and chlorine forming carbonates, sulphates, chlorides and small amounts of silicates. A fixed-bed furnace with temperature $1100-1200{ }^{\circ} \mathrm{C}$ for wood fuels and $1000-1100{ }^{\circ} \mathrm{C}$ for straw was used to make such conclusions.

Obernberger et al. [39] in an analysis of the various inorganic elements in biomass fuels, noted that $\mathrm{Si}$ in combination with $\mathrm{K}$ can lead to the formation of low melting silicates in fly-ash particles, $\mathrm{K}$ is relatively volatile, forming chlorides, hydroxides and sulphates which plays an important role in corrosion. Ca also forms chlorides and sulphates but is less volatile than $\mathrm{K}$ and generally increases the melting point of ashes which are also true for $\mathrm{Mg}$. It was also observed that at higher temperatures and longer heating times, oxides and silicates become dominant. A notable trend also was that silicon and iron are more effectively bound in bottom ash under oxidizing conditions than reducing conditions while Ca was less [9].

\section{Softening and Melting of Ash}

If ash is to be reburnt, the likely conditions under which it softens and melts must be known. Olanders et al. [9] used TGA/DTA determination on ash collected from the same fixed-bed furnace mentioned above, to understand the various temperatures at which softening and melting would occur relative to the biomass type. The research showed that straw ash softened at a much lower temperature than wood/bark. Initial softening of straw ash was at $700{ }^{\circ} \mathrm{C}$ and melting occurred at $975-1025{ }^{\circ} \mathrm{C}$. On the other hand, wood bark softened at $1000-1200{ }^{\circ} \mathrm{C}$ and had a melting point of $1480{ }^{\circ} \mathrm{C}$. Ohman et al. [40] showed initial melting at $850-1025{ }^{\circ} \mathrm{C}$. According to the research, the lowest melting temperature when stored bark was used as fuel, occurred at $866 \pm 7^{\circ} \mathrm{C}$. All other samples had temperatures between $980{ }^{\circ} \mathrm{C}$ and $1025{ }^{\circ} \mathrm{C}$. The research concluded that the total ash and critical inorganic elements in some raw materials could result in ash related problems such as slagging and the forming of deposits on burners. They showed that the elemental distribution in the slag samples varied significantly between samples for different fuels. According to Vamvuka [20], fixed bed ash softens at $1221{ }^{\circ} \mathrm{C}$ and fluidises at $1258^{\circ} \mathrm{C}$ for olive kernel ash. On the other hand, fluid bed fly ash softens at $1293{ }^{\circ} \mathrm{C}$ and fluidises at $1360{ }^{\circ} \mathrm{C}$ for the same ash. When combustion takes place in fixed beds, these should be operated at temperatures below $1100^{\circ} \mathrm{C}$, to avoid ash melting and accompanying problems.

A number of researchers have tried to determine the likelihood of slagging and fouling occurring. While a definite number cannot be ascertained, equations have helped in such predictions. According to Ohman et al. [40] slagging is considered to be the melting of ash. Two important parameters are the alkali index (AI) and the base-to-acid ratio $\left(\mathrm{R}_{\mathrm{b} / \mathrm{a}}\right)$ of wood-ash [24].

Vamvuka [20] noted that the alkali index (AI) expresses the quantity of alkali oxides in the fuel per unit of fuel energy:

$$
\mathrm{AI}=\mathrm{kg}\left(\mathrm{K}_{2} \mathrm{O}+\mathrm{Na}_{2} \mathrm{O}\right) / \mathrm{GJ}
$$


According to Vamvuka [20], when AI values are in the range $0.17-0.34 \mathrm{~kg} / \mathrm{GJ}$ fouling and slagging is probable, while when these values are greater than 0.34 fouling or slagging is virtually certain to occur.

The base-to-acid ratio $\left(\mathrm{R}_{\mathrm{b} / \mathrm{a}}\right)$ can also be used to help determine the likely hood of fouling of the ash. This can be written as follows [24]:

$$
R_{\mathrm{b} / \mathrm{a}}=\frac{\%\left(\mathrm{Fe}_{2} \mathrm{O}_{3}+\mathrm{CaO}+\mathrm{MgO}+\mathrm{K}_{2} \mathrm{O}+\mathrm{Na}_{2} \mathrm{O}\right)}{\%\left(\mathrm{SiO}_{2}+\mathrm{TiO}_{2}+\mathrm{Al}_{2} \mathrm{O}_{3}\right)}
$$

The label for each compound makes reference to its weight concentration in the ash. As $\mathrm{R}_{\mathrm{b} / \mathrm{a}}$ increases, the fouling of a fuel ash increases.

A number of researchers have also investigated the addition of other compounds to minimize or prevent softening or melting of the ash. Ninomiya et al. [41] showed that efficient gasification of a particular coal depends, sensitively on the melting behaviours of the ash produced from that coal and that the high melting temperature ash can be controlled by adding basic oxides which cause a decrease in ash melting temperatures and slag viscosity. The work showed that $\mathrm{CaCO}_{3}$ additive is an efficient fluxing element for the control of ash melting, particularly, $\mathrm{Al}_{2} \mathrm{O}_{3}$-rich ash melting [20]. Wilen et al. [42] also suggested that the addition of a powdery additive, kaolin, talc and ceramic feldspar would increase the fusion temperature. While this would increase the cost of pellets by $5 \%$ and also increase the ash content thereby lowering the heating value, it would also result in cheaper maintenance and equipment cost.

\section{Conclusions}

Biomass based energy systems for heat and electricity will have an important place in the overall energy setup to meet increasing consumer demands. Woody biomass in the form of wood chips, wood residue, planer shavings, sawdust etc. forms the basis for most combustion processes that uses the energy value of this waste material. All of these combustion systems produce a significant amount of ash, which varies from $5 \%$ to $15 \%$ (by weight) of biomass processed. A careful evaluation of data for wood residue and wood chips, the two major sources of wood biomass available for energy generation, shows us that current use levels are well below potential. These facts along with the shift towards cleaner and carbon neutral fuels are expected to contribute to an exponential increase in ash production across the world. This has significant implications for waste management and handling. The limited understanding of ash behaviour, properties and its long-term environmental impacts pose a risk in the scenario of excessive ash generation. The importance of better technologies for producing energy from biomass is also significant. Improved technologies that produce less ash volumes and increase carbon reduction should be considered to assist in ash management related issues.

Ash utilization is limited by the presence of heavy metals and other inorganic compounds, which are formed as a result of the thermochemical reactions that the biomass undergoes when combusted. The variability in heavy metal concentration in ash arises from the differences in properties of feedstock, and hence no singular inorganic composition profile for ash is true. Subsequently, no one application will be suitable for all kinds of ash. Inefficiencies in boilers and furnaces also result in high percentages of unburned organic matter in ash. This carbon content may be recycled to the boiler or furnace to improve energy output and increase the process efficiency. Suggested uses for ash includes 
the application of ash as agricultural fertilizers, as a fuel due to the presence of high unburned carbon content and/or as an additive in construction materials.

The presence of alkali metals, alkaline earth metals, chlorine, sulphur and silicon influences the reactivity and leaching to the inorganic phases. Ash may be utilized as a neutralizing and liming agent. Research also indicates that bottom ash has significantly lower concentrations of heavy metals than fly ash, as such, a mixture of fly ash and bottom ash may be suitable for application as a soil amendment to forest soils. This should assist in maintaining the nutrient cycling instead of landfilling these important nutrients.

Unburned carbon present in ash allows for the exploration of using ash as a fuel. This unburned organic matter has been investigated as a fuel source in some studies that suggest recirculation of ash, increasing residence times and increasing material turbulence inside the boiler. The presence of carbon in ash limits its applications as it decreases its binding properties in construction material. The high carbon content also presents challenges for pelletization and briquetting as it decreases the binding properties.

The need for other ash processing methods should be investigated. We propose sieve fractionation as a suitable method for the separation of unburnt carbon present in bottom ash obtained from a fixed-bed combustion system, followed by the application of the gasification technology to particle sizes of energy importance. The use of the gasification technology in the reduction of ash-carbon content and the ability to recover any useful energy in the combustion residue presents promising prospects. Sieve fractionation may also assist in identify fractions in bottom ash with high organic/carbon content and those with high mineral content as well their impact on the overall volume of ash stored or disposed of.

If ash is to be reburnt, the likely conditions under which it softens and melts must be known since this may cause severe negative impacts on the combustion equipment leading to corrosion. It is expected that the production of bottom ash will increase greatly; therefore, continued research is needed to find suitable applications and processing technologies for ash.

\section{Acknowledgments}

The authors wish to thank the librarians at the Geoffery R. Weller Library, University of Northern British Columbia for their assistance in sourcing reference materials at short requests. We would also like to thank Francis Appoh and other members of the academic committee who gave moral support to the preparation of this manuscript.

\section{References}

1. Demirbas, F.; Balat, M.; Balat, H. Potential contribution of biomass to sustainable energy development. Energy Convers. Manag. 2009, 50, 1746-1760.

2. Saidur, A.; Abdelaziz, E.; Demirbas, A.; Hossain, M.; Mekhilef, S. A review on biomass as a fuel for boilers. Renew. Sustain. Energy Rev. 2010, 15, 2262-2289.

3. Sandberg, J.; Karlsson, C.; Fdhila, R. A 7 year long measurement period investigating the correlation of corrosion, deposit and fuel in a biomass fired circulated fluidized bed boiler. Appl. Energy 2011, 88, 99-110. 
4. Yoon, S.; Son, Y.; Kim, Y.; Lee, J. Gasification and power generation characteristics of rice husk and rice husk pellet using a downdraft fixed-bed gasifier. Renew. Energy 2011, 42, 1-5.

5. Ryu, C.; Yang, Y.; Khor, A.; Yates, N.; Sharifi, V.; Swithenbank, J. Effect of fuel properties on biomass combustion: Part 1. Experiments-fuel type, equivalence ratio and particle size. Fuel 2006, $85,1039-1046$.

6. Gomez-Barea, A.; Vilches, L.; Campoy, M.; Fernandez-Pereira, C. Plant optimization and ash recycling in fluidised waste gasification. Chem. Eng. J. 2009, 146, 227-236.

7. Khan, A.; Jong, W.; Jansens, P.; Spliethoff, H. Biomass combustion in fluidized bed boilers: Potential problems and remidies. Fuel Process. Technol. 2009, 90, 21-50.

8. Demirbas, A. Potential applications of renewable energy sources, biomass combustion problems in boiler power systems and combustion related environmental issues. Prog. Energy Combust. Sci. 2005, 31, 171-192.

9. Olanders, B.; Steenari, B. Characterization of ashes from wood and straw. Biomass Bioenergy 1994, 8, 105-115.

10. Quaak, P.; Knoef, H.; Stassen, H. Energy from Biomass, A Review of Combustion and Gasification Technologies; World Bank: Washington, DC, USA, 1999.

11. FAO STAT. Available online: http://faostat3.fao.org/ (accessed on 15 June 2012).

12. Thrän, D.; Kaltschmitt, M. Biomass for sustainable energy provision systems-State of technology, potentials and environmental aspects. In World Renewable Energy Congress VII; Sayigh, A.M., Ed.; Pergamon: Oxford, UK, 2002.

13. Lövgren, L. Roll pelletizing of ash-Cost efficient handling and improved product with accelerated carbonatization. In Procedings of Conference on Ash Utilization 2012: Ashes in a Sustainable Society, Stockholm, Sweden, 25-27 January 2012.

14. Van Alkemade, I.; Loo, S.; Sulilatu, W. Exploratory Investigations into the Possiblities of Processing Ash Produced in the Combustion of Reject Wood; Netherland Organization for Applied Scientific Research (TNO): Apeldoorn, The Netherlands, 1999.

15. McKendry, P. Energy production from biomass (part 1): Overview of biomass. Bioresour. Technol. 2002, 83, 37-46.

16. Obernberger, I.; Supancic, K. Possiblities of ash utilization from biomass combustion plants. In Proceedings of the 17th European Biomass Conference and Exhibition, Hamburg, Germany, 29 June-3 July 2009.

17. Parikka, M. Global Biomass fuel resources. Biomass Bioenergy 2004, 27, 613-620.

18. Kaltschmitt, M.; Neubart, J. Biomass for Energy: An Option for Covering the Energy Demand and Contributing to the Reduction of GHG Emissions. In Integrating Biomass Energy with Agriculture, Forestry and Climate Change Policies in Europe, London, UK, December 2000.

19. National Renewable Energy Laboratory (U.S.); United States. Department of Energy; United States. Department of Energy. Office of Scientific and Technical Information; Morris, G. The Value of the Benefits of U.S. Biomass Power. The Office of Scientific and Technical Information, U.S. Department of Energy: Washington, DC, USA, 2000.

20. Vamvuka, D. Comparative fixed/fluidized bed experiments for the thermal behavious and environmental impact of oliive kernel ash. Renew. Energy 2009, 34, 158-164. 
21. Wang, L.; Weller, C.; Jones, D.; Hanna, M. Contemporary issues in thermal gasification of biomass and its application to electricity and fuel production. Biomass Bioenergy 2008, 32, 573-581.

22. Nurmesniemi, H.; Manskinen, K.; Poykio, R.; Dahl, O. Forest fertilizer properties of the bottom ash and fly ash from a large-sized (115 MW) industrial power plant incinerating wood-based biomass residues. J. Univ. Chem. Technol. Met. 2012, 47, 43-52.

23. Moilanen, M.; Pietilainen, P.; Issakainen, J. Longterm effects of apatite and biotite ont the nutrient status and stand growth of scots pine (Pinus sylvestris L.) on drained peatlands. Suo (Helsinki) 2005, 56, 115-128.

24. Dahl, O.; Nurmesniemi, H.; Poykio, R.; Watkins, G. Heavy metal concentrations in bottom ash and fly ash fractions from a large-sized (246 MW) fluidized bed boiler with respect to their Finnish forest fertilizer limit values. Fuel Process. Technol. 2010, 91, 1634-1639.

25. Reijinders, L. Disposal, uses and treatments of combustion ashes: A review. Resor. Conserv. Recycl. 2005, 43, 313-336.

26. Minnesota Office of Environmental Services. Issue document: Managing Mn/DOT environmental liability resulting from use of regulates solid wastes in Mn/DOT administered transportation systems. Part 1 Coal ash. Available online: http://www.dot.state.mn.us/environment/research (accessed on 1 June 2012).

27. Bahadori, A.; Vuthaluru, H. Estimation of potential saving from reducing unburned combustible losses in coal-fired sysytems. Appl. Energy 2010, 87, 3792-3799.

28. Duan, L.; Liu, D.; Chen, X.; Zhao, C. Fly ash recirculation by bottom feeding on aa circulating fluidized bed boiler co-burning coal sludge and coal. Appl. Energy 2012, 95, 295-299.

29. Turner, W.; Doty, S. Energy Management Handbook, 6th ed.; Fairmont Press: Lilburn, GA, USA, 2007.

30. Batra, V.; Urbonaite, S.; Svensson, G. Characterization of unburned carbon in bagasse fy ash. Fuel 2008, 87, 2972-2976.

31. Overview of Gasification Technology. Available online: http://cturare.tripod.com/ove.htm (accessed on 13 March 2010).

32. Rade, K.; Karamarkovic, V. Energy and exergy analysis of biomass gasification at different temperatures. Energy 2010, 35, 537-549.

33. Lövgren, L.; Lundmark, J.; Jansson, C. Adaptation for Recycling of Bio Asashes: Evaluation of New Technologies for Pelleting of Bio Ash with Respect to the Operational Characteristics, and Environmental Impacts in the Forest; Project P11647-1; Swedish National Energy Administration: Eskilstuna, Sweden, 2000.

34. Svantesson, T.; Petersson, T.; Jedfelt, D. Evaluation of Trial Roll Pelleting Method; Technical Report for Automated Manufacture of Fertilizing Agglomerates from Burnt Wood Ash; University of Kalmar: Nybro, Sweden, 2004.

35. Sarenbo, S.; Melbo, P.; Stalnacke, O.; Claesson, T. Reactivity and Leaching of wood ash pellets dehydrated by hot air and flue gas. Open Waste Manag. J. 2009, 2, 47-54.

36. Jianguo, J.; Maozhe, C.; Yan, Z.; Xin, X. Pb stabilization in fresh fly ash from municipal solid waste incinerator using accelerated carbonation technology. J. Hazard. Mater. 2009, 161, 1046-1051. 
37. Zhang, H.; Hem, P.; Shao, L.; Lee, D. Temporary stabilization of air pollution control residues using carbonation. Waste Manag. 2008, 28, 509-517.

38. Liao, C.; Wu, C.; Yan, Y. The characreristics of inorganic elements in ashes from a $1 \mathrm{MW}$ CFB biomass gasification power generation pplant. Fuel Process. Technol. 2007, 88, 149-156.

39. Obernberger, I.; Biedermann, F.; Widmann, W.; Riedl, R. Concentrations of inorganic elements in biomass fuels and recovery in the different ash fractions. Biomass Bioenergy 1997, 12, 211-224.

40. Ohman, M.; Boman, C.; Nordin, A.; Bostrom, D. Slagging tendencies of wood pellet ash during combustion in resendtial pellet burners. Biomass Bioenergy 2004, 27, 585-596.

41. Ninomiya, Y.; Sato, A. Ash melting behaviour under coal gasification conditions. Energy Convers. Manag. 1997, 38, 1405-1412.

42. Wilen, C.; Stahlberg, P.; Sipila, K.; Ahokas, J. Pelletization and combustion of straw. Energy Biomass Waste 1987, 10, 469-484.

(C) 2012 by the authors; licensee MDPI, Basel, Switzerland. This article is an open access article distributed under the terms and conditions of the Creative Commons Attribution license (http://creativecommons.org/licenses/by/3.0/). 